\title{
A note on nursing ethics in the USA
}

Martin Bunzl Department of Philosophy, University of Minnesota

In this note on nursing ethics, Mr Martin Bunzl, a philosopher who is involved in seminars on medical ethics at his university, describes the ethical dilemmas of the nurse in the USA. He sets out the arguments to support the view that a nurse ought always to follow the orders of the physician and critically evaluates them both from an ethical and a legal standpoint. The practical implications of the view that a nurse's responsibility is to do what is in the best interests of patients are also discussed.

Despite the recent plethora of papers discussing medical ethics, little or no attention has been paid to ethical problems that are unique to the practice of nursing. In the case of physicians, there is little controversial in the claim that their responsibility is to their patients. Certainly there are disagreements as to what that responsibility entails: for example, whether or not it entails perpetuating the life of the patient under all circumstances. And certainly there are disagreements as to who is to be considered a patient: for example, does the classification of patients include just those patients who are the immediate object of a physician's attention or does it also include their relatives? But despite these disagreements, the uncontroversial claim can still be made that the physician's responsibility (whatever that entails) is to his or her patients (whomsoever they are). On the other hand, the responsibilities of most other hospital personnel seem pretty easy to define as well. If they have any responsibilities, they do not entail direct responsibilities to the patients: rather, their direct responsibilities are to their superiors. But nurses seem to be placed in a special and unique position - caught between two poles. On the one hand, they are expected to be responsible to physicians, and yet, at the same time, they are held to be responsible directly to their patients. The view that nurses have a primary responsibility to physicians finds quintessential expression in the seventh paragraph of the 1965 International Council of Nursing Code of Ethics: 'The nurse is under an obligation to carry out the physician's orders intelligently and loyally ....

Requests for reprints should be sent to Martin Bunzl, Department of Philosophy, Ford Hall, Minneapolis, Minnesota 55455.
The other pole between which nurses seem to be $\vec{\circ}$ caught finds expression in the revised code of ethics for nurses issued in 1973: 'The nurse's primary $\vec{\omega}$ responsibility is to those people who require? nursing care .... I interpret this to mean that the ${ }_{\bar{\sigma}}^{3}$ nurse's overriding responsibility is to do what is inthe best interests of those persons requiring his or: her immediate care.

\section{Nurses between two ethical poles}

While the 1965 code of ethics makes no mention of nurses having any kind of direct responsibility to patients requiring their care and the 1973 revision? of the code of ethics no mention of nurses having any responsibility to follow physician's orders, both $\overrightarrow{0}$ of these seem quite reasonable demands, so whyo should this be a problem? If we make one assumption, there obviously is no problem, namely, that physicians always act in the best interests of those people who require medical care. But suppose that this assumption sometimes does not hold and that the dictates of the 1965 code of ethics stand in conflict with the dictates of the 1973 code of ethics, what then? Is a nurse's primary responsi- 3 bility to do what is in the best interests of patients under his or her care or is it to follow the orders of the physician intelligently and loyally? I should 3 note in passing that the seventh paragraph of the International Council of Nursing's code of ethics (1965) presents the nurse with another dilemmas namely, what she should do when presented with ans order by a physician that entails an unethica 5 procedure. According to the first part of the paragraph, he or she is under an obligation to carryo out that order intelligently and loyally, yet accordingto the second part of that paragraph, he or she is under an obligation to refuse to participate in tho procedure. Of course if we assume that any pron cedure that is not in the interests of the patient is $\omega$ unethical, the first dilemma is subsumable within the second.

\section{A nurse's primary responsibility is to the doctor?}

It seems to me that there are a number of argument命 that support the view that a nurse's primary responsibility is to the physician and not to the patient and that, therefore, a nurse should alway 
follow the orders of a physician even in cases where it is not in the best interest of patients under his or her care. First, in view of the fact that physicians represent a scarce resource in society, they can best be utilized by a maximally efficient division of labour, best effected by physicians giving orders and others implementing them on behalf of those physicians. After all, in most cases, it is by virtue of a physician's expertise in diagnosis and treatment that he or she is considered a scarce resource. But if such a maximally efficient division of labour is to be implemented, it is essential for physicians to have working with them staff who will follow their orders. After all, in a climate of mistrust a physician is hardly going to be able to delegate responsibility confidently for the implementation of his orders. And furthermore, it is, after all, the physician, in virtue of his specialized training, who is best placed to make judicious decisions for the benefit of patients under his care. However, it is certainly inevitable that physicians will make erroneous judgments and that patients will therefore suffer. Even so, if the most efficient way for medicine to function is through a maximal division of labour, and if such a division of labour requires that personnel comply with the orders of physicians, the suffering that ensues from compliance with erroneous orders will be less than the suffering that would ensue from a less efficient organization of medical care.

\section{The premise in the hierarchical organization of medicine}

How tenable are these arguments? From an empirical standpoint, they obviously rest on the crucial premise that a hierarchical organization of medical personnel with a maximal division of labour will result in the most efficient form of health care. Certainly most forms of medical health care are predicated upon this premise, but this fact in itself does not constitute evidence for the truth of the premise. Empirical claims aside, these arguments seem to generate a morally abhorrent conclusion. How could any one be an agent in the visitation of needless suffering upon a patient when he knew that the suffering could be avoided? Certainly, when nurses enter employment, they also enter into a contractual agreement to follow physician's orders. From this agreement there flows an obligation to follow those orders. But this does not seem a strong enough justification for the visitation of needless suffering upon patients. What does seem necessary to justify such a state of affairs is the knowledge that were such orders not followed, the system of health care would collapse, resulting in the visitation of more suffering than that associated with the existing system. While we may believe this to be the case, such belief does not constitute knowledge in the absence of justification for that belief - something we are currently lacking.

\section{Negligence in nurses in law in the USA}

There is another problem in the view that nurses ought to have a primary responsibility to physicians. One would think that if this view could be sustained morally, then the law ought to uphold it. Perhaps it ought to, but it does not. Nurses can be held liable under the law for actions they commit even when they are following the orders of physicians. According to civil law, a nurse can be held negligent when he or she knowingly implements orders with the knowledge that their implementation will cause harm to the patient. Furthermore, a nurse can even be held liable if he or she was ignorant of the consequences of the implementation of such orders but such ignorance was due to a deficit of expertise, where such expertise could have been reasonably expected judging by the standards of the profession (Lesnik and Anderson, I94I). The fact that a nurse was following a doctor's order is not in itself a defence, rather it is the fact that the nurse could not have been reasonably expected to know that the implementation of the orders would be injurious to the patient (Murphy, Heiland, and Adamson, 1974).

Let us suppose that a nurse's primary responsibility is to do what is in the best interests of the patient, the doctor's orders notwithstanding. What are the practical implications of this view?

A practical implication for most nurses seems to be that they will lose their jobs if they fail to comply with the orders of physicians. What ought a nurse to do when confronted with a dilemma of following a physician's orders for whatever reason, when she knows that obeying such orders will not be in the best interests of the patient? Obviously, when confronted with such a situation, a nurse can and ought to bring such objections to the attention of the physician, either directly or through a person standing in between the nurse and the physician in the hierarchy of the hospital. But what if this fails? What if the physician rejects the nurse's objections, or if the nurse's superior refuses to pass on such objections? Can a nurse act in such a way that will prevent harm to the patient and yet ensure that his or her job will not be placed in jeopardy? One option was recently raised in a class discussion held in a medical ethics course taught at the University of Minnesota. In that class, nurses related instances in which nurses refused to implement orders given by physicians when they believed those orders not to be in the best interest of their patients, but falsified patient records to show that such orders had indeed been implemented. Such a course of action can hardly be considered a judicious solution to the dilemma. A physician, prescribing a certain dosage of a drug and failing to see the predicted reaction in the 
patient, might order an increase in the dosage, assuming that the patient had an extremely high tolerance to the drug in question. However, the results of the implementation of such an order for an increased dosage might be injurious to the patient, and, while the nurse who refused to implement the physician's original order might refuse to implement the order for an increased dosage, the vagaries of hospital scheduling might well result in another nurse or the physician obeying the order. Another option frequently suggested is that the nurse's obligation extends only to refusing to implement the order herself but not to preventing others from fulfilling it. However, this position is hardly tenable either. It seems to rest on the view that acts of omission cannot be subjected to moral evaluation. But why should this be the case? We make moral judgments about acts of omission every day - you were wrong to stand by idly while that man was in need of help, you would have wanted him to help you if you had been in his shoes - and they seem to fit into our moral framework just as well as our judgments about acts of commission. If the nurse's objection to an order is in virtue of the fact that it is not in the interest of the patient and if the nurse sees herself as having a direct responsi-m bility to act in a manner that is in the best interest $-\overrightarrow{\bar{n}}$. of the patient, then the nurse has an obligation tow? see that no harm comes to that patient, be it through $\Rightarrow$ her agency or through the agency of another person.

In this note I have tried to point out the way in? which nurses are caught in two kinds of dilemmas in을 virtue of their particular position in the hospital? hierarchy. One dilemma involves whether or not@ they should do what is in the best interests of patients or follow the physician's orders when the two are in conflict. The other is more practical. If ${ }_{-}^{\circ}$ the nurses are under an obligation to do what is in $\vec{\omega}$ the best interests of the patients, can they do so in such a way that will not result in a loss of their jobs?

\section{References}

The American fournal of Nursing (1973), 73, 1351

Lesnik, M, and Anderson, B (194I). Nursing Practice and the Law, Lippincott, 1962

Murphy, J, Hetland, J, and Adamson, O (1974), Minnesota Practice, Volume 4, Minnesota Jury Instruction Guides. Civil, West, JIGII, 432 